\title{
Effect of intralipid administration on calcium therapy in verapamil toxicity
}

\author{
Baltaci Ozen S, Celebi SH, Coskun D, Gungor I, Inan G \\ Department of Anaesthesiology and Reanimation, Gazi University Faculty of Medicine, Ankara, Turkey. \\ dcoskun@gazi.edu.tr
}

\begin{abstract}
Aim: Lipid emulsions are promising with regard to the treatment of toxicity by agents of high lipophilic nature. Our objective is to investigate the efficacy of intralipid $20 \%$ and calcium administration at different times when symptoms of cardiac toxicity occur during verapamil infusion.

Method: 24 adult male Spraque-Dawley rats were randomly divided into 4 different groups, the control group, calcium group, calcium following $20 \%$ intralipid group and concomitant $20 \%$ intralipid and calcium group. Following monitoring under ketamine anesthesia, all groups were administered $37.5 \mathrm{mg} \mathrm{kg}^{-1} \mathrm{~h}^{-1}$ verapamil infusion until a $50 \%$ decrease occurred in $\mathrm{MAP}_{\mathrm{b}}$. At the end of the infusion, verapamil infusion was decreased down to $15 \mathrm{mg} \mathrm{kg}^{-1} \mathrm{~h}^{-1}$ and the treatment agents predetermined for the groups were administered concomitantly.

Results: There is no statistically significant difference between the administration of $20 \%$ intralipid synchronized with calcium or as a pretreatment, but both groups provided a higher survival rate when compared to the other groups.

Conclusions:The administration of calcium alone in verapamil toxicity is not sufficient; when calcium and $20 \%$ intralipid are administered together, there is no difference between the administration of lipid and calcium concomitantly and the administration of lipid prior to calcium (Tab. 1, Fig. 2, Ref. 23). Text in PDF www.elis.sk. Key Words: Verapamil, toxicity, intravenous lipid emulsion, calcium.
\end{abstract}

\section{Introduction}

The protective and rescue effects of lipid emulsions against bupivacaine toxicity were first demonstrated and supported in advanced studies by Weinberg et al. (1-3). It can also be seen that very recently, intralipid $20 \%$ has taken place in treatment protocols as a rescue agent for local anesthetic systemic toxicity (LAST) (4). Furthermore, lipid emulsions have become promising for the treatment of toxicity due to an overdose of other agents with their high lipophilic nature, and have even been suggested as an antidote. In this group, mainly beta blockers, calcium channel blockers and tricyclic antidepressants have been experimentally studied (5-8). Among these agents, the most significant one is verapamil, a calcium channel blocker, due to its high lipid solubility. Lipid rescue therapy has proven to be quite effective in studies about verapamil overdose (9-11).

This study is based on the hypothesis that in verapamil toxicity model in rats, the administration of intralipid $20 \%$ prior to calcium removes verapamil and makes the binding of calcium to channels easy. The objective is to determine the improvement in

Department of Anaesthesiology and Reanimation, Gazi University Faculty of Medicine, Ankara, Turkey

Corresponding Author: Demet Coskun, MD, Gazi University Faculty of Medicine, Department of Anesthesiology and Reanimation, 06500-Ankara, Turkey cardiac parameters and survival rates when intralipid 20\% and calcium are administered at different times and to compare the efficiency of treatment methods.

\section{Materials and methods}

This study was performed at Gazi University Faculty of Medicine Experimental Animals Research Center, with the approval of the Local Animal Ethics Committee (GU.ET-66332047-604.01.0215.018). In the study, 24 adult male Spraque Dawley rats weighing between 250-350 $\mathrm{g}$ were used. The experimental animals were adapted to the environment by being kept at $20 \pm 2^{\circ} \mathrm{C}$ for seven days, 12 hours in day light and 12 hours in the dark until the start of the experiment. The subjects were fed on standard pellet rat feed and water.

The rats were randomly divided into 4 groups with 6 rats assigned in each group. The administration of normal saline as loading dose and infusion in the control group (Group C), calcium in the same volume of saline as loading dose and infusion in the calcium group (Group Ca), calcium as loading dose and infusion after intralipid 20\% (Fresenius Kabi AB, Upsala, Sweden) as loading dose and during intralipid 20\% infusion in the intralipid and calcium group (Grup L-Ca), intralipid $20 \%$ and calcium concomitantly as loading dose and infusion in the concomitant intralipid and calcium group (Grup L $+\mathrm{Ca}$ ) was planned. In order to ease the procedures, head and abdominal fur of the rats that were anesthetized with intramuscular $50 \mathrm{mg} \mathrm{kg}^{-1}$ ketamine (12) were shaved. 
During the study, the rats were kept in supine position with their extremities fixed. The rate and rhythm of the heartbeat of the rats were followed in $\mathrm{D}_{2}$ derivation and the rats were monitored (MINDRAY Patient Monitor PM-8000 Express, Shenzhen Mindray BioMedical Electronics Co., Ltd.). When sufficient anesthetic depth was ensured, surgical tracheostomy was performed for controlled respiration. 16 or $18 \mathrm{G} \mathrm{IV}$ cannula was placed according to the diameter of the trachea. The tail vein was cannulated with $24 \mathrm{G} \mathrm{IV}$ cannula for the administration of the study drugs and for hydration. Following tracheostomy, for the administration of muscle relaxant $0,1 \mathrm{mg} \mathrm{kg}^{-1} \mathrm{~min}^{-1}$ vecuronium bromide was administered as a bolus, and respiration was maintained at $100 \% \mathrm{O}_{2}, 4 \mathrm{~L} \mathrm{~min}^{-1}$ fresh gas flow, $12 \mathrm{~mL} \mathrm{~kg}^{-1}$ tidal volume and $40-55$ breaths per minute via an automatic ventilator (Harvard Rodent Model, Inspira ASV, Hollstone, MA, USA). Abdominal aorta was surgically cannulated with $26 \mathrm{G}$ cannula for the monitaring of invasive systemic artery pressure and blood gas control. Invasive artery pressure monitoring was performed through a transducer connected to the arterial cannula. The study drugs and the fluids were administered via an infusion pump (B Braun Melsungen AG-products-Perfusor ${ }^{\mathrm{R}}$ Spase, Germany). Upon the completion of invasive procedures, the electrocardiograms and invasive blood pressure of the rats were monitored and following stabilization (10 minutes), heart rates $\left(\mathrm{T}_{\mathrm{b}}\right)$ and mean arterial pressures $\left(\mathrm{T}_{\mathrm{b}}\right)$ were recorded as baseline values.

Then, the experiment was started by administering verapamil (Isoptin, Abbott Laboratories, Abbott Park, IL, USA) infusion at a rate of $37.5 \mathrm{mg} \mathrm{kg}^{-1} \mathrm{~h}^{-1}$. During verapamil infusion, the time of HR's decreasing below $50 \%$ and/or the time of MAP's decreasing below $50 \%\left(\mathrm{~T}_{0}\right)$ when compared to the control $\left(\mathrm{T}_{\mathrm{b}}\right)$ were recorded. When MAP and/or HR decreased below 50\%, verapamil infusion was reduced down to $15 \mathrm{mg} \mathrm{kg}^{-1} \mathrm{~h}^{-1}$ and simultaneously treatment agents predetermined for the groups were administered. In group $\mathrm{C}$, $0.9 \% \mathrm{NaCl}$ was loaded at a rate of $12.4 \mathrm{~mL} \mathrm{~kg}^{-1}$ in 10 minutes and then the infusion was maintained at the same rate for 50 minutes. In group Ca, calcium $12.4 \mathrm{~mL} \mathrm{~kg}^{-1}$ in $\% 0.9 \mathrm{NaCl} 0.2 \mathrm{mmol} \mathrm{kg}^{-1}$ loading dose was given in 10 minutes, and the infusion was maintained at the same rate for 50 minutes. In group L-Ca, a loading dose of intralipid $20 \% 12.4 \mathrm{~mL} \mathrm{~kg}^{-1}$ was given in 10 minutes and while the infusion was maintained at the same rate for 50 minutes, calcium $0.2 \mathrm{mmol} \mathrm{kg}^{-1}$ loading dose was given in 10 minutes and calcium at the same rate as maintenance dose was administered for 40 minutes concomitantly. In group $\mathrm{L}+\mathrm{Ca}$, intralipid $20 \% 12.4$ $\mathrm{mL} \mathrm{kg}^{-1}$ and $0.2 \mathrm{mmol} \mathrm{kg}^{-1}$ calcium was loaded in 10 minutes, and then $12.4 \mathrm{~mL} \mathrm{~kg}^{-1} \mathrm{~h}^{-1}$ intralipid $20 \%$ and $0.2 \mathrm{mmol} \mathrm{kg}^{-1} \mathrm{~h}^{-1}$ calcium infusion was maintained for 50 minutes.

The time of the heart rate's decreasing below $50 \%$ compared to the initial value, the time of the mean arterial pressure's going below $50 \%$ compared to the initial value $\left(\mathrm{T}_{0}\right)$ and $\mathrm{HR}$ and MAP once every 10 minutes $\left(\mathrm{T}_{0}, \mathrm{~T}_{10}, \mathrm{~T}_{20}, \mathrm{~T}_{30}, \mathrm{~T}_{40}, \mathrm{~T}_{50}, \mathrm{~T}_{60}\right)$ were recorded. In the first 60 minutes of the experiment, rhythm disturbances and asystole times were recorded. The rats that did not die within the preset period of time were euthanized by the removal of intracardiac blood for follow-up.

Statistical analysis was performed using SPSS for Windows Version 20.0 package program. Mean \pm standard deviation, me- dian, minimum and maximum values of weight, MAP and HR of the rats were analyzed descriptively. Kruskal Wallis test was performed to analyze whether there was a difference among the treatment groups regarding the weight, MAP and HR values of the rats nonparametrically. Following the analysis, Mann Whitney U test was performed among pairs of groups in order to determine the group from which the difference resulted. The variance of the successive measurement values of MAP and HR values of the rats was studied using repeated mixed linear model analysis. In cases where sphericity variance was not provided, Greenhouse-Geisser correction was used. The total type-1 error level was determined as $5 \%$ for statistical significance. Survival probability among the subjects according to the treatment groups was calculated using Kaplan-Meier Survival analysis. In all the analyses performed, $\mathrm{p}<0.05$ values were considered statistically significant.

\section{Results}

When studied hemodynamically, a general decrease in MAP and HR parameters draws attention in all groups at all measurement times after the administration of verapamil when compared to $\mathrm{Tb}$ measurement time. It has been demonstrated that there was no difference in the mean arterial pressure (MAP) values of the rats following stabilization $\left(\mathrm{T}_{\mathrm{b}}\right)$ at $\mathrm{T}_{0}$ and $\mathrm{T}_{60}$ while there was a statistically significant difference $(\mathrm{p}<0.05)$ among the groups at $\mathrm{T}_{10}, \mathrm{~T}_{20}$, $\mathrm{T}_{30}, \mathrm{~T}_{40}$ and $\mathrm{T}_{50}$. When a comparison was made among the pairs of groups in terms of MAP values in repeated measurements, no statistically significant differences were found between the control group and the L $+\mathrm{Ca}$ group, and between the L-Ca group and the $\mathrm{L}+\mathrm{Ca}$ group. It was observed that the MAP values of the rats in the L-Ca group were higher than of those in the control group at $\mathrm{T}_{20}$ and $\mathrm{T}_{50}(\mathrm{p}<0.05)$. It was found out that the MAP values of the rats in the L-Ca group were higher than of those in the Ca group at $\mathrm{T}_{10}, \mathrm{~T}_{20}, \mathrm{~T}_{30}$ and $\mathrm{T}_{40}(\mathrm{p}<0.01)$. As for the MAP values of the Ca group and the $\mathrm{L}+\mathrm{Ca}$ group, there were statistically significant differences at $\mathrm{T}_{20}, \mathrm{~T}_{30}, \mathrm{~T}_{40}$ and $\mathrm{T}_{50}(\mathrm{p}<0.01)$; and the MAP values of the rats in the $\mathrm{L}+\mathrm{Ca}$ group were higher than of those in the $\mathrm{Ca}$ group (Figure 1).

According to the results of the repeated measurements of heart rate $(H R)$, there were statistically significant differences $(p<0.05)$ among the groups at $\mathrm{T}_{\mathrm{b}}, \mathrm{T}_{20}, \mathrm{~T}_{30}, \mathrm{~T}_{40} \mathrm{~T}_{50}$ and $\mathrm{T}_{60}$. In the pair comparisons made among the groups, no statistically significant differences were found between the control group and the Ca group. It was observed that HR results of the control group and the L-Ca group demonstrated statistically significant differences $(\mathrm{p}<0.01)$ at $\mathrm{T}_{30}, \mathrm{~T}_{40}, \mathrm{~T}_{50}$ and $\mathrm{T}_{60}$ and that the HR measurement results in the L-Ca group were higher than of those in the control group. As for the $\mathrm{HR}$ values obtained from the control group and the $\mathrm{L}+\mathrm{Ca}$ group at $\mathrm{T}_{\mathrm{b}}, \mathrm{T}_{20}, \mathrm{~T}_{30}, \mathrm{~T}_{40}, \mathrm{~T}_{50}$ and $\mathrm{T}_{60}$, the HR values were statistically higher in the $\mathrm{L}+\mathrm{Ca}$ group $(\mathrm{p}<0.01)$. It was found out that there was a statistically significant difference between the Ca group and the L-Ca group at $\mathrm{T}_{30}$ and $\mathrm{T}_{40}(\mathrm{p}<0.01)$; and that $\mathrm{HR}$ values in the L-Ca group were higher than of those in the Ca group. When the $\mathrm{Ca}$ group and the $\mathrm{L}+\mathrm{Ca}$ group were compared, $\mathrm{HR}$ values were found to be statistically higher at $\mathrm{T}_{20}, \mathrm{~T}_{30}, \mathrm{~T}_{40}$ and $\mathrm{T}_{50}(\mathrm{p}<0.01)$. 


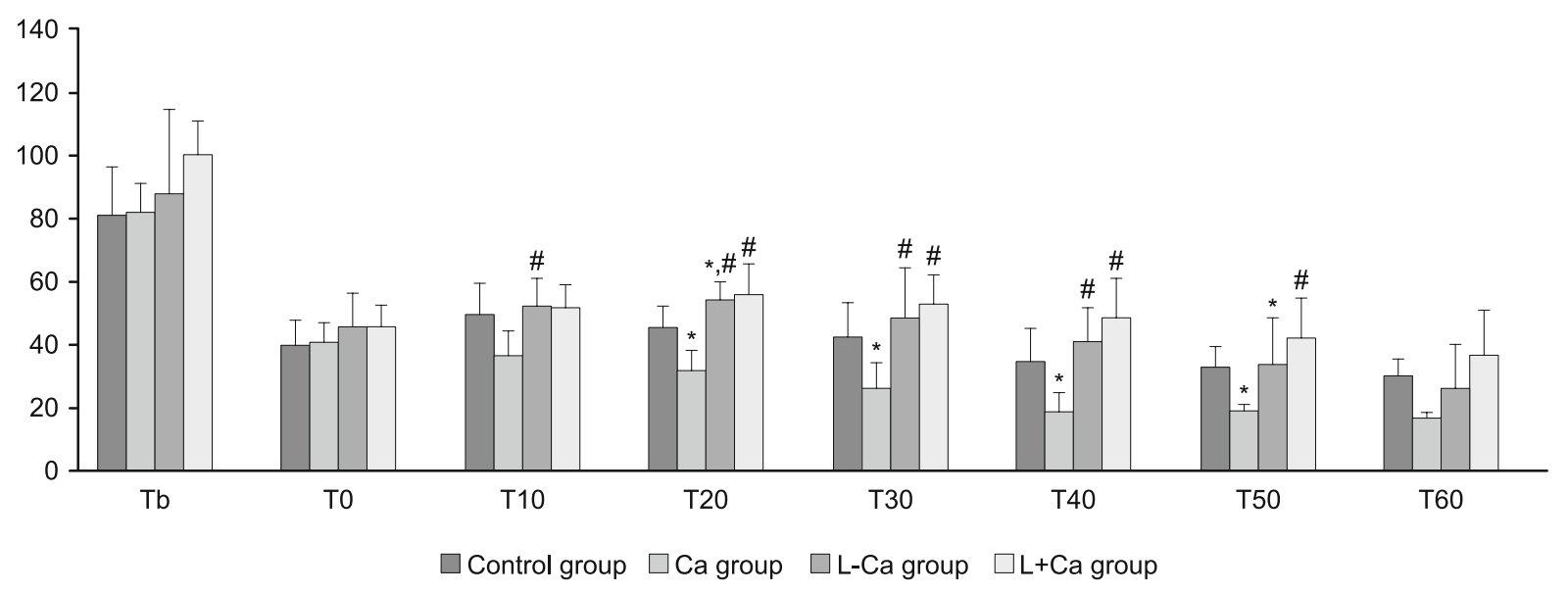

Figure 1. Change of MAP measured at different times according to groups $* \mathbf{p}<0.05$, according to the control group $\# \mathbf{p}<\mathbf{0 . 0 5}$, according to Ca group

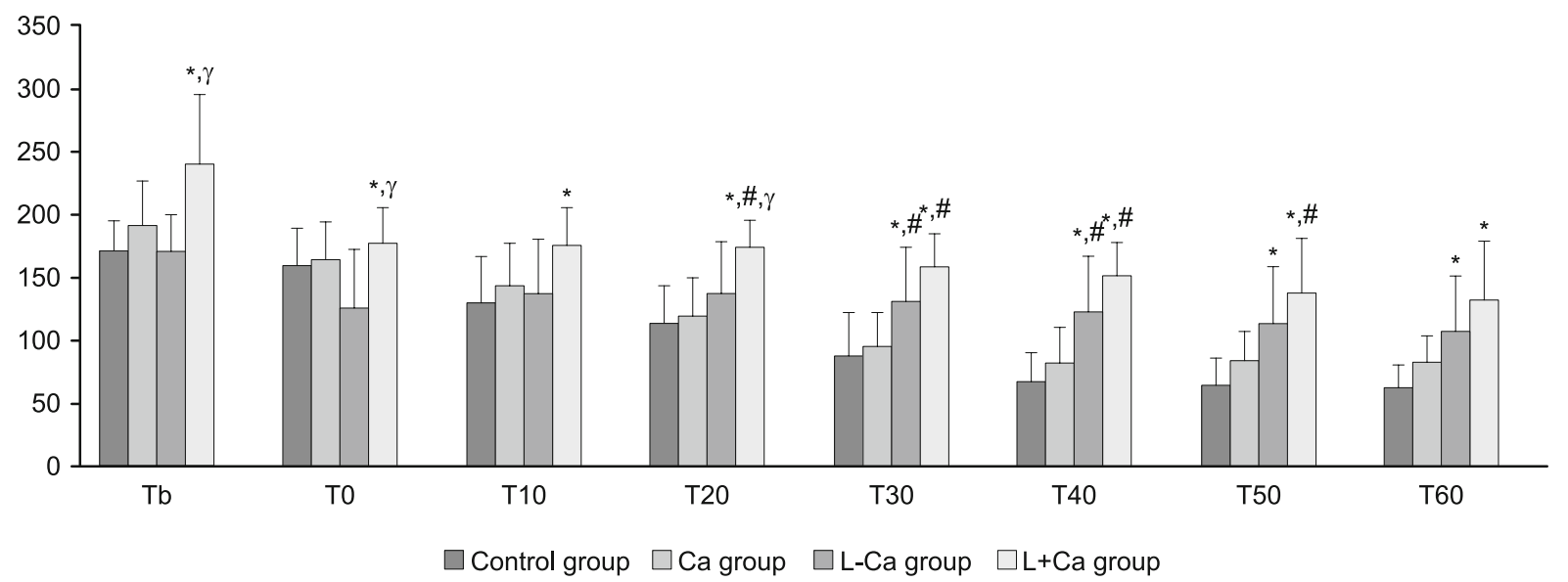

Figure 2. Change of HR measured at different times according to groups

$* \mathbf{p}<0.05$, according to the control group

$\# \mathbf{p}<0.05$, according to Ca group

$\gamma \mathbf{p}<\mathbf{0 . 0 5}$, according to $\mathbf{L}-\mathrm{C}$ a group

It can also be seen that there was a statistically significant difference between the L-Ca group and the $\mathrm{L}+\mathrm{Ca}$ group at $\mathrm{T}_{\mathrm{b}}$ and $\mathrm{T}_{20}$ $(\mathrm{p}<0.01)$, and that the HR values in the $\mathrm{L}+\mathrm{Ca}$ group were higher than of those in the L-Ca group (Figure 2).

During follow-up, while the survival rate was $83.3 \%, 66.7 \%$, $66.6 \%$ and $50 \%$, respectively at $\mathrm{T}_{50}$ and $\mathrm{T}_{60}$ in control and $\mathrm{Ca}$ groups to which lipid was not administered, it was found to be $100 \%$ at $\mathrm{T}_{50}$ and $\mathrm{T}_{60}$ in both $\mathrm{L}-\mathrm{Ca}$ and $\mathrm{L}+\mathrm{Ca}$ groups to which lipid was administered (Table).

\section{Discussion}

Verapamil is a calcium channel blocker with high lipid solubility frequently used in angina pectoris, supraventricular cardiac arrhythmia and hypertension. In toxic doses, bradycardia, rhythm disorders, atrioventricular block, hypotension and cardiogenic shock may develop due to sinoatrial depression. Toxicity develops
Table. Survival rates according to treatment groups

\begin{tabular}{lccccc}
\hline Groups & $\mathrm{n}$ & $\begin{array}{c}\text { Number } \\
\text { of ex (n) }\end{array}$ & $\begin{array}{c}\text { Survived for } \\
60 \min (\mathrm{n})\end{array}$ & $\begin{array}{c}\text { Survival at } \\
50 \min (\%)\end{array}$ & $\begin{array}{c}\text { Survival at } \\
60 \mathrm{~min}(\%)\end{array}$ \\
\hline Control & 6 & 2 & 4 & 83.3 & 66.7 \\
$\mathrm{Ca}$ & 6 & 3 & 3 & 66.6 & 50 \\
$\mathrm{~L}-\mathrm{Ca}$ & 6 & 0 & 6 & 100 & 100 \\
$\mathrm{~L}+\mathrm{Ca}$ & 6 & 0 & 6 & 100 & 100 \\
\hline Total & 24 & 5 & 19 & 87.5 & 79.2 \\
\hline
\end{tabular}

with the decrease of intracellular calcium in cardiac and vascular muscles. With low doses in verapamil toxicity, intravenous calcium goes from the extracellular compartment towards the cell and binds to the unblocked channels while in high doses, as too many channels are blocked, treatment with calcium as a single agent is not sufficient. Mainly calcium, glucagon and insulin, and atropine in the case of bradycardia are used in the treatment $(13,14)$. In another study performed, it was demonstrated that the combina- 


\section{9-793}

tion of calcium and digoxin increases systolic blood pressure and does not result in ventricular arrhythmia in dogs. In that study, the importance of drug combinations was highlighted and it was reported that digoxin at therapeutical doses increased intracellular calcium, and calcium addition increased the contractile capacity of digoxin and thus increased blood pressure (15).

Regarding the studies about lipid treatment, in the rat model where verapamil toxicity was formed with continuous infusion, it was shown that intralipid treatment doubled the survival rate and mean fatal dose when compared to the control group and also prevented bradycardia caused by verapamil. Therefore, it was suggested that intralipid treatment would be useful for toxicity due to lipid soluble drugs (9). In a study they conducted, Bania et al. (10) considere $50 \%$ MAP decrease as the start of toxicity during verapamil infusion to dogs, then decreased the verapamil dose and following atropine and calcium chloride treatment, formed two groups, the lipid group and the normal saline group. This study showed that in the lipid group, blood pressure and survival rate increased. In the dose study by Perez et al. (11), it was reported that in the treatment of verapamil toxicity, a dose of 18.6 $\mathrm{mL} \mathrm{kg}^{-1}$ lipid emulsion provides high survival. Van de Velde et al. (16) reported that lipid emulsions decrease verapamil overdose by generating energy in the myocardium cells in the form of free fatty acid. A study that was previously conducted in our clinic using lipid emulsions with different triglyceride structures showed that in a rat model of verapamil toxicity, intralipid $20 \%$ as well as medialipid $20 \%$ solutions also similarly eliminated cardiodepressant effects and increased survival rate (12).

In the systematic review where they examined the treatments and the results of those treatments practiced in the toxicity of calcium channel blockers, St-Onge et al. (17) evaluated the level of proof of high doses of insulin and application of extracorporeal circulation as low, whereas the level of proof of calcium, dopamine, norepinephrine and epinephrin treatment as very low. When lipid emulsion treatment is evaluated, it has been stated that in animals, intravenous $20 \%$ intralipid treatment at a dose range of $6.2-18.6$ $\mathrm{mL} \mathrm{kg}^{-1}$ improves hemodynamics and survival.

It has been stated that although the rescue effect of lipid emulsions in treatment of LAST due to bupivacaine has been proven and a practice guide has been established, there are authors that state a similar rescue protocol may not be valid for verapamil since while bupivacaine binds to cardiac sodium channels very strongly, verapamil binds to calcium channels, and it is too early to designate that lipid solutions are life saving antidotes for verapamil and similar drugs $(18,19)$. However, in verapamil toxicity cases, clinical improvement was observed following the administration of lipid emulsion in the course of treatment after various treatment methods were tried (20-22). There is even a case presentation that reports the benefits of intralipid $20 \%$ administration not only in the late phase, but also in the first line treatment of toxicity (23). In our study, we wanted to observe the variation in the efficacy of lipid emulsions when administered at different times in verapamil toxicity treatment.

In our study, the main objective was to remove verapamil, which has a high solubility in lipids, from calcium channels in a rat model of verapamil toxicity. The reason for us to choose this approach is based on the 'Lipid Sinking' theory of lipid emulsions. It is suggested that lipid molecules bind lipophilic drugs and for this reason, they incarcerate lipid soluble toxic substances in circulation and make them sink in the emulsion (2-4). Our expectation was to remove verapamil from the occupied calcium channels and ensure that calcium reached the intracell rapidly. To this end, a combination of $20 \%$ intralipid emulsion and calcium chloride was selected. Our hypothesis was based on the idea that the administration of $20 \%$ intralipid prior to calcium would remove verapamil and make the binding of calcium to channels easier. Our results showed that there is no difference between the administration of $20 \%$ intralipid synchronized with calcium or as a pretreatment, but both groups provided a more efficient cardiac recovery and a higher survival rate when compared to the control group and the group that was treated with calcium only.

In our research protocol, verapamil toxicity was targeted as the $50 \%$ MAP decrease time and was performed over this parameter. A standard could not be ensured as the cardiac rhythm records evaluated simultaneously were higher in one group than in the others at the beginning. However, this is an issue that cannot be controlled by the researchers. This could be considered as a limitation of our research.

We concluded that the use of calcium as a single agent is not sufficient for the treatment of verapamil toxicity; that regarding the combination of calcium and intralipid $20 \%$, there is no difference between the concomitant administration of lipid and calcium and as a pretreatment; and that both groups provided a more effective cardiac recovery and a higher survival rate when compared to the control and calcium groups. On the other hand, although our study indicates the useful effect of the combined administration of these two agents, baseline blood pressure values could not be reached in the selected period of time. For this reason, we believe that advanced studies which investigate other treatment options in addition to the concomitant administration of calcium and intralipid $20 \%$ for the improvement of hypotension are required.

\section{References}

1. Weinberg GL, VadeBoncouer T, Ramaraju GA, Garcia-Amaro MF, Cwik MJ. Pretreatment or resuscitation with a lipid infusion shifts the dose-response to bupivacaine-induced asystole in rats. Anesthesiology 1998; 88 (4): 1071-5.

2. Weinberg G, Ripper R, Feinstein DL, Hoffman W. Lipid emulsion infusion rescues dogs from bupivacaine-induced cardiac toxicity. Reg Anesth Pain Med 2003; 28 (3): 198-202.

3. Weinberg GL, Ripper R, Murphy P, Edelman LB, Hoffman W, Strichartz G, Feinstein D. Lipid infusion accelerates removal of bupivacaine and recovery from bupivacaine toxicity in the isolated rat heart. Reg Anesth Pain Med 2006; 31 (4): 296-303.

4. Neal JM, Mulroy MF, Weinberg GL. American Society of Regional Anesthesia and Pain Medicine Checklist for Managing Local Anesthetic Systemic Toxicity: 2012 version. Reg Anesth Pain Med 2012; 37 (1): 16-8.

5. Turner-Lawrence D E, Kerns W. Intravenous fat emulsion: A potential novel antidote. J Med Toxicol 2008; 4 (2): 109-14. 
6. Cave G and Harvey M. Intravenous lipid emulsion as antidote beyond local anesthetic toxicity: a systematic review. Acad Emerg Med 2009; 16 (9): 815-24.

7. Jamaty C, Bailey B, Larocque A, Notebaert E, Sanogo K, Chauny JM. Lipid Emulsions in the treatment of acute poisoning: a systematic review of human and animal studies. Clin Toxicol 2010; 48 (1): 1-27.

8. Hoegberg LCG and Gosselin S. Lipid resuscitation in acute poisoning: After a decade of publications, what have we really learned?Current Opinion in Anaesthesiology2017; 30 (4): 474-9.

9. Tebbutt S, Harvey M, Nicolas T, Cave G. Intralipid prolongs survival in a rat model of verapamil toxicity. Acad Emerg Med 2006; 13 (2): 134-9.

10. Bania T, Chu J, Perez E, Su M, Hahn IH. Hemodynamic effects of intravenous fat emulsion in an animal model of severe verapamil toxicity resuscitated with atropin, calcium, and saline. Acad Emerg Med 2007; 14 (2): 105-11.

11. Perez E, Bania C, Medlej K, Chu J. Determining the optimal dose of intravenous fat emulsion for treatment of severe verapamil toxicity in a rodent model. Acad Emerg Med 2008; 15 (12): 1284-9.

12. Akgün Şahin F, Çelebi SH, Güngör İ, Coşkun D, Ergüven Kaya E. Therapeutic effects of intralipid and medialipid emulsions in a rat model of verapamil toxicity. Turk J Med Sci 2016; 46 (1): 1568-72.

13. Tuncok Y, Apaydın S, Kalkan S, Ateș M, Güven H. The effects of amrinon and glucagon on verapamil induced cardiovascular toxicity in anaesthetized rats. Int J Exp Pathol 1996; 77 (5): 207-12.

14. Salhanick SD and Shannon MW. Management of Calcium Channel Antagonist Overdose. Drug Safety 2003; 26 (2): 65-79.
15. Bania TC, Blaufeux B, Hughes S, Almond GL, Homel P. Calcium and Digoxin vs Calcium Alone for Severe Verapamil Toxicity. Acad Emerg Med 2000; 7 (10): 1089-96.

16. Van de Velde M, WoutersPF, Rolf N, Van Aken H, Flameng W, Vandermeersch E. Long-Chain triglycerides improve recovery from myocardial stunning in conscious dogs. Cardiovasc Res 1996; 32 (6): 1008-15.

17. St-Onge M, Dubé PA, Gosselin S, Guimon C, Godwin J, Archambault PM, et al. Treatment for calcium channel blocker poisoning: A Systematic review. Clin Toxicol 2014; 52 (9): 926-44.

18. Gueret G, Pennec JP, Arvieux CC. Haemodynamic effects of intralipid after local anaesthetics intoxication may be due to a direct effect of fatty acids on myocardial voltage-dependent calcium channels. Ann Fr Anesth Reanim. 2010; 29 (9): 661.

19. Butterworth JF. Models and Mechanism of local anesthetic cardiac toxicity. Reg Anesth Pain Med 2010; 35 (2): 167-76.

20. Young AC, Velez LI, Kleinschmidt KC. İntravenous fat emulsion therapy for intentional sustained-release verapamil overdose. Resuscitation 2009; 80 (5): 591-3.

21. Liang CW, Diamond S, Hagg DS. Lipid rescue of massive verapamil overdose: a case report. J Med Case Reports 2011; 5: 399.

22. French D, Armenian P, Ruan W, Wong A, Drasner K, Olson KR, et al. Serum verapamil concentrations before and after Intralipid therapy during treatment of an overdose. Clin Toxicol 2011; 49 (4): 340-4.

23. Akıncı E, Köylü R. Verapamil Poisoning, the Importance of Intravenous Lipid Therapy: Case Report. JAEMCR 2013; 4: 130-2.

Received June 3, 2019. Accepted July 12, 2019. 